\title{
Reescritura y crítica en la era digital: Reversiones de crítica y literatura en los blogs de Cristina Rivera Garza y Vicente Luis Mora ${ }^{1}$
}

\section{Rewriting and Criticism in the Digital Age: Reversals of criticism and literature in the blogs of Cristina Rivera Garza and Vicente Luis Mora}

\author{
Juan José Mendoza \\ UBA/UNA/IIBICRIT-SECRIT/CONICET, Argentina \\ juanse.mendoza@gmail.com \\ Mariano Ernesto Mosquera \\ UBA/CONICET, Argentina \\ marianoernestomosquera@gmail.com \\ Andrés Olaizola \\ ILH-FFYL/UBA, Argentina \\ aolaizola@gmail.com
}

\footnotetext{
${ }^{1}$ El presente trabajo forma parte de un proyecto colectivo, más amplio, intitulado: "Maneras de leer en la era digital: formas de representación de la literatura y el pasado en el siglo Xxı", dirigido por Juan J. Mendoza y realizado a instancias de la UBA, UNA y el IIBICRIT-SECRIT/CONICET. Como tal, aquí se retoman trabajos anteriores (Mendoza, 2011, 2014) y, en particular, consideraciones en torno al Remodernismo (Mendoza, 2016), entre otras.
} 
Resumen: El presente artículo procura, a partir del examen de dos blogs de literatura y crítica en español, rastrear los avatares de la crítica y "las trayectorias de la escritura como proceso" en el cruce entre cultura libresca y era digital. A partir de la lectura de No hay tal lugar de Cristina Rivera Garza (2002 y continúa) y Diario de lecturas de Vicente Luis Mora (2004 y continúa), el artículo rastrea los modos de aparición de la crítica, procurando una reflexión en torno a las páginas en línea de los escritores como lugares de intervención, como laboratorios de la propia escritura, como lugar de producción de enunciados provisorios, lugar de construcción de archivos de autor y como obras interactivas. Hacia el final del artículo, se examinan los modos de aparición de la tradición literaria en el presente: la reescritura de textos caros a la tradición de la modernidad, las pervivencias del canon, la vigencia en el siglo xxI de antiguos debates del campo.

Palabras clave: reescritura, crítica, era digital, Cristina Rivera Garza, Vicente Luis Mora.

Abstract: This article seeks, from the examination of two blogs of literature and criticism in Spanish, to trace the "avatars of criticism" and "the trajectories of writing as a process" in the cross between bookish culture and digital age. From the reading of No hay tal lugar by Cristina Rivera Garza (2002 and continues) and Diario de lecturas by Vicente Luis Mora (2004 and continues), the article traces the ways of appearance of criticism in blogs in general; and the online pages of writers as places of intervention, as writing laboratories, as a place of production of provisional statements, place of construction of author files and as interactive and online works. Towards the end of the article, the ways of appearance of the literary tradition in the present are examined: the rewriting of expensive texts to the tradition of modernity, the survivors of the canon, the validity in the 21 st century of ancient debates in the field. 
Keywords: Rewriting, Criticism, Digital Age, Cristina Rivera Garza, Vicente Luis Mora.

Recibido: 14 de febrero de 2020

Aceptado: 20 de abril de 2020 https://dx.doi.org/10.15174/rv.vi26.529

\section{Avatares de la crítica en la era digital}

Como antaño Borges, que desde las páginas de la Revista Multirevista Sur ensayaba sus primeras versiones de Historia universal de la infamia y El Aleph. O como antaño Edgar Allan Poe, que desde las páginas de Graham's Magazine lanzaba las primeras versiones de "Los crímenes de la calle Morgue" o su crítica a Twice-Told Tales de Nathaniel Hawthorne. Del mismo modo, son muchos los escritores que desde la primera década del siglo xxI utilizan sitios webs como lugar de inscripción de las intervenciones críticas y las ficciones que luego reversionarán y enviarán a la imprenta. Desde 2003, cuando Google adquiere Blogger, la plataforma de Pyra Labs que había sido lanzada el 23 de agosto de 1999, los blogs se han abierto paso como lugar de intervención crítica, como laboratorio de escritura, como taller de enunciados provisorios, como archivos de autor, como obras interactivas y en línea. La irrupción de los blogs significó una importante transformación de grado respecto de los modos de intervención crítica en el campo cultural de la era digital. Al tiempo que en los primeros años de la década 00 la aparición de los blogs atomizó aún más la dispersión del campo literario y cultural que se venía gestando desde los 90, del mismo modo, poco a poco la escalada y la aceleración de la Internet 2.0 -la de Twitter y Facebook, la de las redes sociales- ha hecho que la potencia crítica de la web de los primeros años del siglo Xxi se 
fragmentara hasta incluso disiparse y extraviarse bajo el imperio de los algoritmos de tendencias. Hay sin embargo muchos blogs que perviven, que cobijan su potencia crítica a fuerza de una enorme resistencia dentro del género. Tal es el caso de sitios como linkillo.blogspot.com de Daniel Link o de cippoweb.com.ar de Rafael Cippolini en Argentina, dedicados al cruce entre crítica literaria, crítica de arte y, al mismo tiempo, consagrados ellos mismos también como hilos suspicaces, obras en línea, singulares marcas de poeticidad en medio del runrún cibernético.

Cristina Rivera Garza y Vicente Luis Mora, en parte en España, México y en EE.UU. -Rivera Garza es docente en diversas universidades de México y Profesora de la Universidad de Houston-, vienen alimentando y haciendo crecer casi ininterrumpidamente sus blogs en español desde los orígenes de blogger. Cristina Rivera Garza trabaja con la noción de "Escrituras Colindantes". Vicente Luis Mora lo hace a bordo de "deslizamientos" entre literatura e imagen. Ambos utilizan el cruce de géneros. Y usan en distinto grado sus propias entradas de blog como borradores de los libros y de los volúmenes de ensayos que, luego, envían a la imprenta. Inspirados en páginas de papel, las intervenciones críticas que alimentan la línea del scroll de sus blogs viajan hasta los Data Centers en los que se alojan sus líneas cargadas de potencia crítica. Y, luego, retornan de las casas editoriales que las reimprimen en letras de molde, en un incesante vaivén que lleva las páginas de papel a los blogs y las entradas de los blogs que se compilan en volúmenes de ensayos otra vez al papel; recopilaciones de blogs que luego aparecen posteadas en Instagram. Todo en un Péndulo de Foucault que bambolea y bate cultura letrada con bibliotecas de ficción, intervención crítica y mucha era digital, en un furibundo pulso que todavía tiene al pasado y a la modernidad como ominoso espejo negro de fondo. 
Para Vicente Luis Mora, en particular, las tecnologías narrativas del siglo xxi han producido un nuevo tipo de textualidad -caracterizada por una composición expandida de la letra o, precisamente, definida por su carácter Textovisual-y han producido un sinnúmero de nuevos tipos de lectura. Las video-reseñas y los textos-links que reenvían de una referencia a otra son de algún modo las formas de emergencia de esos "nuevos" tipos de lecturas, nuevos objetos de estudio. "Escrituras en marcha" ["Escriturasenmarcha”], Lecturas en directo o Críticas en vivo ["Críticaenvivo"], pergeńan el nuevo glosario que nace del cruce entre informática y cultura del libro.

\section{CRG: No hay tal lugar y las escrituras colindantes}

No hay tal lugar fue abierto el 22 de noviembre de 2002 [http:// cristinariveragarza.blogspot.com/]. En aquel momento el blog se llama Words are the very eyes of secrecy. Desde entonces Cristina Rivera Garza ha estado alimentando de escritura No hay tal lugar, el cual se ha conformado en un espacio para la experimentación literaria; el desarrollo de reflexiones sociales, políticas, culturales; el análisis sobre su propia poética y la escritura autobiográfica. En la publicación del 1 de enero de 2003, Rivera Garza anuncia que desde ese día, y durante un ańo, publicará una "blognovela" por entregas: "Diré que hace tiempo he querido hacer esto: seguir los designios de la escritura errante. Sin borradores. Sin correcciones. Sin versión final” (Rivera Garza, 2003c). Luego, en la entrega del 26 de febrero, leemos: "La novela, susurrará de la manera más arrebatada posible, sí vela. La novela esconde, oculta, deforma, oscurece, opaca. [...] De ahora en adelante, [...] la novela se referirá a sí misma como la sívela" (Rivera Garza, 2003b).

El cambio responde a una trayectoria conceptual que se aleja de la transparencia. Para Rivera Garza, uno de los mitos de la novela 
moderna es su función de "productora de esa muy particular forma de conocimiento que es la iluminación"; por lo tanto, ella propone la "blogsívela", que "se erige orgullosa de sus propias sombras, de sus muchos trucos de velación” (2004b: 178). A partir de la blogsivela, Rivera Garza espera leer y escribir, en papel o en la pantalla, novelas semiherméticas, "que puedan velar -en el sentido de ocultar y proteger, y también de trasnochar y custodiar- el mundo en el momento mismo en que producen los significados dentro de los cuales existe ese mundo" (178-179). En 2004 su blog cambia de nombre. En el post del 8 de enero de ese año Rivera Garza escribe: "No hay tal lugar. Nunca lo hubo. Nunca lo habrá" (Rivera Garza, 2004a). Desde aquel año el blog empieza a llamarse con su denominación actual: No hay tal lugar. U-tópicos contemporáneos. ${ }^{2}$

\section{Primera aproximación}

You-Jeong Choi (2006, 2007, 2010), Françoise Griboul (2006) y Betina Keizman (2013) analizaron No hay tal lugar. A grandes rasgos coinciden en destacar que el blog traza ininterrumpidamente trayectorias múltiples y simultáneas, que lo llevan a cruzar las fronteras entre los géneros, los lenguajes, las textualidades, las culturas. Keizman (2013) propone identificar dos "zonas de trabajo" en el blog: la del "diario de escritor", integrada por borradores de textos, experimentos escriturales, traducciones, ensayos sobre la propia poética; y la de la esfera artística, cultural y social, que desarrolla prácticas de reflexión y de producción ligadas al campo de las artes y de la participación política (5). En No hay tal lugar suelen formularse "series de imágenes y texto vinculadas por un título, en donde ensaya sucesivos abordajes a un tema determinado". Las

${ }^{2}$ En la primera etapa del blog, Rivera Garza firmaba sus posts como "cristina", en la segunda, hasta la actualidad, "crg". 
series delinean formas de cohesión entre textos que pueden parecer desligados (Keizman, 2013: 7).

Una periodización del blog permite rastrear no solo las dinámicas de la escritura digital de Rivera Garza, sino también el modo en que ésta se relaciona con sus publicaciones impresas. Hay instancias en las que el blog es, en efecto, la ventana de inicio hacia nuevos textos: "un sitio de orientación, un portal, un generador de actividades" (Bourriaud, 2014: 16).

Una primera etapa del blog abarcaría las publicaciones de noviembre y diciembre de 2002 y todas las del año 2003. El principal elemento de esta etapa es la blogsívela. Además de los lineamientos estéticos que la impulsan, éste es el primer texto digital del blog que luego va a ser remezclado en un texto posterior: en el poemario de Los textos del yo (2005b).

Una segunda etapa del blog se extiende desde el 2004 hasta el 2009. Este período queda inaugurado con el nuevo nombre del blog. A su vez, el blog comienza a ejecutar roles en performances organizadas por Rivera Garza, ya sea como parte del aparato de difusión y como soporte de exhibición para los objetos/textos derivados de ellas, ${ }^{3}$ pero también como posible punto de partida para futuras acciones. En esta segunda etapa, en el blog se empiezan a reproducir los artículos de "La mano oblicua", columna que desde 2006 a 2013 Rivera Garza escribió para el periódico mexicano Milenio, muchos de los cuales van a ser reformulados en Dolerse. Textos desde un país herido (2011) y Los muertos indóciles. Necroescrituras y desapropiación (2013).

Una tercera etapa va del 2010 al 2013. Entre esos años Rivera Garza desarrolla la mayor cantidad de producciones digitales

${ }^{3}$ La Inquietante (e Internacional) Semana de las Mujeres Barbudas, anunciada en la publicación del 25 de junio de 2005; y la Semana de las Mujeres Invisibles, convocada en la publicación del 1 de marzo de 2006. 
que luego continuarán resonando en otros medios y textos. Rivera Garza retoma un personaje secundario de La muerte me da, la Increíblemente Pequeña, y expande el mundo de la historia (Ryan, 2013) de la novela a partir de diez publicaciones de una "fotonovela diurna". ${ }^{4}$ Luego, la Increíblemente Pequeña protagoniza siete episodios más de la fotonovela, que pueden encontrarse en https:// increiblementepequena-blog.tumblr.com/.

Entre junio y julio 2010 se publica la serie "Un verde asi", que consiste en fotografías que se caracterizan por un verde intenso. Debajo de la imagen del objeto, lugar, insecto o sujeto se agregan, en un montaje que juega con la correspondencia (o no) entre palabra e imagen, textos de prosa poética que a menudo recurren a la cita en itálica de distintas fuentes, ya sean "canónicas" -Juan Rulfo, Ramón López Velarde, Anne Michaels, etc.- como de la comunidad tuitera-@altanoche, @frank_lozanodr, @viajerovertical, entre otros-. Luego, en Viriditas (2011), ${ }^{5}$ Rivera Garza propondrá un nuevo itinerario para recorrer "Un verde así": enmarca la serie entre dos posteos inéditos del 24 de diciembre de 2010, agrega uno del 17 de abril de 2010 y a continuación reproduce todas las entregas sobre el color verde sin las fotografías.

De octubre de 2010 a enero de 2011, en el blog también se publica la serie "Telegramas para dos increíblemente pequeńas forajidas", que conforma un ruego delineado por una consigna de escritura derivada de los límites técnicos del telegrama, ${ }^{6}$ pero

${ }^{4}$ Publicaciones del 24 de septiembre, 9 de octubre, 13 de octubre, 16 de octubre, 23 de octubre, 7 de noviembre, 18 de noviembre, 16 de diciembre y 24 de diciembre del 2010. Publicación del 1 de enero de 2011.

${ }^{5}$ Para un análisis de Viriditas vinculado con el concepto de colindancia se sugiere Cruz Arzabal (2014, 2016).

${ }^{6}$ [El texto se escribirá a doble renglón entre líneas y en mayúscula sostenida / No se deberán dividir silábicamente las palabras / Se deberán eliminar palabras innecesarias como: artículos, conjunciones y preposiciones / Se usarán términos 
también por el lenguaje desnudo que se enuncia a causa de unas ausencias. Los telegramas son reinsertados luego en la fotonovela de la Increíblemente Pequeña y son el eje central de la sección "Me llamo cuerpo que no está: los enclíticos”, del poemario La imaginación pública (2015).

Entre el 26 de diciembre de 2010 al 27 de septiembre de 2011, también se publica en el blog la serie "Mi Rulfo mío de mí", en la que, a través de distintos procedimientos, se reescriben los 26 primeros fragmentos de Pedro Páramo. Los ecos textuales de esta lectura/escritura pueden rastrearse en Habia mucha neblina o humo o no sé qué (2016).

Un último periodo de producción del blog abarca los años 2014 a 2019. De forma sostenida (salvo en 2017), el número de publicaciones se va reduciendo hasta llegar a tan solo unos diecinueve posteos en todo el 2019.

\section{No hay tal lugar_ las trayectorias sin fin}

Para Rivera Garza la razón principal por la que decidió abrirse un camino en la plataforma blog se funda en una investigación de sí: "quería saber qué le pasaría a mi escritura en este nuevo medio y, más generalmente, quería saber también qué le podría pasar a la escritura en la blogósfera” (2004b: 169).

La escritura en los entornos digitales interconectados, según Rivera Garza, permite cuestionar "el mito de la novela terminada" (176). El blog evidencia que la escritura nunca termina, que siempre hay reescritura, que está en-proceso-de-ser escritura constantemente. La reescritura "deshace lo ya hecho, mejor aún, lo vuelve un hecho inacabado, o termina dándolo por no hecho en lugar de

enclíticos, como "solicítole”, “agradecémosle” / Se deberá, en lo posible, utilizar palabras que no pasen de 10 caracteres] (Rivera Garza, 2010d). 
por hecho; termina dándolo, aún más, por hacer” (Rivera Garza, 2013: 267). ${ }^{7}$

El blog muestra que "esa convención conocida como el final es completamente aleatoria” (Rivera Garza, 2005a). "Todo final decepciona" (Rivera Garza, 2003a), porque suele responder a motivos extra-textuales: "un contrato que se cumple, el aburrimiento del autor, las ganas de iniciar un nuevo libro, una fecha límite", etc. La escritura digital evidencia que el final es "algo, de cualquier modo, prescindible" (Rivera Garza, 2005a). La escritura digital ${ }^{8}$ ayuda a conservar "la posibilidad de que eso que saltó una vez hacia la percepción lo vuelva a hacer desde la página” o la pantalla (Rivera Garza, 2010a: 16).

\section{Trayectorias experimentales: No hay tal lugar como un espacio (en) blanco}

No hay tal lugar conserva "los rasgos principales de los diarios de los escritores” (Keizman, 2013: 5), los cuales, ya había postulado Barthes (1986), responderían a cuatro motivos: desarrollar una escritura individualizada, testimoniar las huellas de una época, constituir al autor "en un objeto de deseo" y convertir al diario en un taller de frases exactas (367). En este último punto, se advierte que el blog de Rivera Garza se configura muy especialmente como laboratorio creativo (Pantel, 2018: 26), en donde no solo se experimenta con la recursividad propia de la escritura digital, sino que se ensayan las potencialidades estéticas de la interfaz multimedia, transmedia, multimodal de las prácticas de lectura y de escritura

\footnotetext{
${ }^{7}$ Retomamos aquí ideas ya desarrolladas con anterioridad en algunos de nuestros trabajos: Mendoza (2011), entre otros.

${ }^{8}$ Sánchez-Aparicio (2016, 2018, 2019) emplea el concepto de "escrituras del software", a las que define como "poéticas disruptivas que provocan un colapso estético".
} 
de, en y a través de los entornos digitales interconectados. Al entrar al blog de Rivera Garza, podemos pensar en los términos en que lo hace Reinaldo Laddaga en Estética de laboratorio (2010): visitamos su taller, su laboratorio de escritura, el lugar de su autoexposición "en condiciones controladas" y en el momento mismo en que el artista se encuentra desarrollando su producción.

Choi (2007) indica que "no hay tal lugar" es la traducción que Alfonso Reyes propone para la palabra utopía, siguiendo a Francisco de Quevedo. No hay tal lugar se define por la presencia antes que por la ausencia, es un espacio utópico en el que están al mismo tiempo todos los lugares por los que la escritura puede explorar sus capacidades estéticas: el blog es un "espacio artístico total”, en donde resuenan los ecos de las aspiraciones vanguardistas del arte total a través de medios técnicos (Keizman, 2013: 6-9).

En El disco de Newton. Diez ensayos sobre el color (2011), la escritura ensayística/poética de Rivera Garza toma la forma del aforismo, del tweet. En la primera sección, leemos: "No es extraño que la libertad sea a veces una gran pared blanca. / El blanco, como se sabe, no es la ausencia de color. A través del disco de Newton, un viejo ejercicio escolar, los nińos aprenden que el blanco resulta de la rápida combinación de todos los colores" (9). El blanco de la pared, de la página, de la pantalla a menudo es la libertad, porque es la suma de todos los colores, los lugares, las trayectorias. Para aprender que el blanco del espacio (del blog) no se trata de la ausencia, sino de la presencia simultánea, opuesta, colindante de géneros, modos, prácticas, hay que experimentar con la escritura, pensando al "experimento como juego", porque evita "la necesidad de percibir a lo experimental como opuesto al realismo narrativo" (Rivera Garza, 2011:31).

En Rivera Garza, el experimento, en tanto juego, no es la ausencia de la narración, es la posibilidad de cualquier tipo de narración en y a través de cualquier tipo de texto o medio. Lo experimental 
trasciende los márgenes del blog: para Rivera Garza (2007a) escribir es el acto físico del pensamiento, "es una experimentación con los límites del lenguaje y, a final y principio de cuentas, un proceso de producción (de significados) (de realidad) (de mundos-otros)" (13).

\section{De la dinámica de la errancia a las escrituras colindantes}

La "escritura errante" a la que Rivera Garza hacía referencia en el anuncio del inicio de la blogsívela es una dinámica de la escritura. La blogsívela era permanente reescritura, era experimentación y, por lo tanto, era movimiento: "Con salidas falsas, con principios repetitivos, con capítulos que no llevan a ningún lado, con finales que se desdicen, la blogsívela se quiere tartamuda, imperfecta, inacabada, en-proceso-perpetuo. A eso yo le llamo la escritura errante, la que erra y la que yerra, el lado más vulnerable de los «lenguajes literarios» que le abre la puerta a la heteroglossia” (Rivera Garza, 2004b: 177).

La escritura errante también podría ser entendida como la manifestación de aquel "arte radicante", siguiendo las ideas de $\mathrm{Ni}$ cholas Bourriaud (2018): un arte concebido a partir del uso de un término de la botánica que designa a las plantas cuyas raíces crecen según su avance. Así, el arte radicante pone en marcha las propias raíces en contextos y formatos heterogéneos y a su vez les niega la virtud de definir completamente su identidad a los sujetos, puesto que traduce ideas, transcodifica las imágenes, trasplanta los comportamientos, intercambia en vez de imponer, etc. (24). La escritura en y del blog asume "la condición del errante, figura central de nuestra era precaria, que emerge y persiste en el seno de la creación contemporánea” (24). Para Rivera Garza la blogsívela en particular, y la escritura digital en general, tendrían a la errancia como dinámica formal de composición, la cual remitiría a "una 
concepción del espacio-tiempo que se inscribe a la vez contra lo lineal y contra lo plano” (Bourriaud, 2018: 118).

El 10 de julio de 2004, Rivera Garza publica "Escrituras colindantes", un post en el que con cierto tono gramsciano postula que tanto "en la vida como en la escritura, lo verdaderamente interesante ocurre en las colindancias -esos espacios volubles donde lo que es no acaba de ser y, lo que no es, todavía no empieza-". A partir de esta reflexión, la escritora elabora el concepto de "escrituras colindantes" que, lejos de entenderse como espacios armónicos en donde se da la posibilidad de una síntesis, se constituyen como "espacios de choque", territorios de "lo diferente, lo disarmónico e, incluso, lo incompatible" (Rivera Garza, 2004e). Ante dos o más lenguas, lenguajes disímiles, las escrituras colindantes lejos de disolver las diferencias en una nueva unidad conservan las características dinámicas de cada una/o (Rivera Garza, 2004f). La colindancia no es hibridación, ni una combinatoria, menos una "nueva forma de fijación" que busca una resolución que es siempre ficticia: la colindancia es errancia permanente, allí se da "la conmoción del encuentro, la tensión que lo genera y que lo sostiene” (Rivera Garza, 2004e).

Las escrituras colindantes, cuya dinámica es la errancia, "no ocurre, no puede ocurrir, en un género literario específico". Así como "lo más interesante (y lo más interesante siempre es más decisivo que lo más correcto o lo más verdadero) de la poesía ocurre en la narrativa, [1]o más interesante de la narrativa ocurre en la poesía”. Las fronteras entre géneros son puestas en cuestión y se explicita "la extrema porosidad de los límites establecidos por los llamados poderes literarios” (Rivera Garza, 2004d).

Las teorizaciones -las experimentaciones- sobre la era digital la conducen a la tradición literaria. Así, las escrituras colindantes encuentran en Juan Rulfo un antecedente central. Los fragmentos, los diálogos escuetos en Rulfo "se resisten al poder amalgamador 
de la anécdota" y se diseminan "hacia direcciones siempre imprevistas, regresando a veces, avanzando y retrocediendo al mismo tiempo otras", con lo que "no solo alejan a Pedro Páramo del realismo nacionalista de su época sino que lo colocan en esa colindancia en que la línea, siendo parte de un párrafo, se acerca sin embargo al verso" (Rivera Garza, 2005c).

$\mathrm{Si}$ en las escrituras colindantes escuchamos los ecos de Rulfo -al que podríamos agregar Amparo Dávila, Macedonio Fernández, Julio Cortázar (Rivera Garza, 2004b), pero también Alejandra Pizarnik, Virginia Woolf, Marguerite Duras (Rivera Garza, 2010c) - son los entornos digitales interconectados los que aumentan su poética. Para Rivera Garza, el blog, desde luego, pero también Twitter (Rivera Garza, 2013), son espacios donde se trazan colindancias, porque su arquitectura hipertextual, multimodalidad, inmediatez y recursividad posibilitan que se componga por "trayecto", para producir textos "cuyo desarrollo permite hacer entrar en resonancia las temporalidades, los espacios y las materias heterogéneas que constituyen los procedimientos" que éstos ejecutan (Bourriaud, 2018: 134-135).

\section{Trayectorias al/del pasado}

Más que pensar a No hay tal lugar como un espacio que, a partir de una directriz vanguardista, trata de "romper el canon de la literatura hispánica" (Choi, 2007), para arribar a una instancia utópica que, libre de pasados, aspire a un "arte total" (Keizman, 2013: 9), el blog emerge como uno de los lugares, una de las trayectorias del "remodernismo" contemporáneo, un fuerte lugar de posición que, desde el siglo Xxi todavía lee y re-escribe "los textos, la cultura y los acontecimientos de la historia en el presente bajo los coordenadas teóricas de la modernidad" (Mendoza, 2016: 74). 
En Rivera Garza, lo experimental es constitutivo del acto de escribir en cualquier soporte, lo cual no invalida al realismo narrativo, antes bien, abre las puertas a otros tipos de realismos, a otras formas de la narrativa. La experimentación trabaja con lenguajes varios, con modos del relato, con las espacialidades y, desde luego, las temporalidades:

Si todo acto de escritura es [...] un acto de activa apropiación de y desde convenciones heredadas y por crearse, entonces ese acto de escritura tiene, por fuerza, aunque no por principio y ni siquiera como finalidad, que ser un acto transgresor - un acto que ańade o trastoca o niega lo real y sus efectos-. Es en este sentido más bien laxo en que concibo todo acto de escritura como una experimentación (Rivera Garza, 2007b: 15).

En No hay tal lugar se ejecutan prácticas de apropiación de géneros, escrituras, tradiciones remotas, recientes y en proceso de crearse. El fragmento de Rulfo, el verso de Pizarnik, el riesgo que aporta Emily Dickinson a la literatura, ${ }^{9}$ El laberinto de la soledad dialogando con Pedro Páramo para producir, cada uno, su propia lectura de la modernidad mexicana (Rivera Garza, 2017: 94-96), Rayuela o Museo de la novela eterna como premonición e invocación de la "blogescritura literaria” (Rivera Garza, 2004b), etc., (re) surgen, se (re)escriben en las publicaciones del blog, más que para enunciar afirmaciones, para formular "la pregunta sobre el canon, el gran tótem remodernista, un superviviente de la modernidad que [todavía] opera con su inercia más allá de ella” (Mendoza, 2016: 74).

9 "Por ahí entra la revisión de formas poéticas heredadas del viejo mundo y la invención de otras nuevas. Por ahí entra la ruptura con la linealidad cronológica, la rima y ritmo singulares, la dislocación de los sentidos del verso, los experimentos con la puntuación. Por ahí entra el riesgo" (crg, 2010b). 
Las convenciones heredadas, las tradiciones, el canon se incorporan al blog como instancias de una trayectoria que no sigue una dirección única, que va y vuelve, pero que nunca se detiene. En las publicaciones de No hay tal lugar, la escritura experimenta con el pasado y al hacerlo, lo registra, lo reconforma a través de nuevas colecciones, nuevos archivos: "El que escribe, registra. El que registra, archiva”. Pero esa relación con lo anterior debe ser siempre activa, ya que acecha la inmovilidad, el olvido: "El que archiva, olvida” (Rivera Garza, 2004e). Para Rivera Garza, el archivo del blog, de la escritura (digital) no debe ser una culminación, sino "el proceso que impide culminarlo" (Rivera Garza, 2007b: 13): un archivo blando, "arcón sin arconte" dirá Claudia Kozak (2015). Un archivo errante entre las colindancias, podríamos también decir aquí. Las múltiples tradiciones literarias que se hacen presentes en No hay tal lugar se alejan de la museificación; en cambio, en sus ecos se reformulan las preguntas que todavía están sin respuestas, y esa pareciera ser una de las motivaciones centrales de las escrituras colindantes: "Uno va al lugar de origen para recordar cosas que no puede entender" (Rivera Garza, 2004c).

Así, los objetos del pasado se instauran como un-archivo-vivoen-blog, que "une a lo-que-es con lo-que-está-a-punto-de-ser y lo-que-no-es" (Rivera Garza, 2004b: 170), para abordarse en las publicaciones "como formaciones contingentes" y establecer con ellas una relación de mantenimiento de posibilidades a punto de perderse o de desbloqueo de posibilidades perdidas (Laddaga, 2010: 206-207). En “Mi Rulfo mío de mí”, Pedro Páramo se (re) fragmenta, se transforman párrafos específicos a través del tachado y del uso del color, sus capítulos se convierten en estrofas de versos libres (Rivera Garza, 2017: 15); en "Las aventuras de la Increíblemente Pequeña”, la fotonovela resuena en el PowerPoint, los telegramas se reproducen como posteos y derivarán en estrofas; en 
"Duras, la ur-blogger" (Rivera Garza, 2007a), Marguerite actualiza su blog desde el pasado, etc.

\section{Una última publicación. Y continuará.}

El 1 de septiembre de 2019 aparece la última publicación de $N o$ hay tal lugar. Quizás allí se ha cerrado una instancia de escritura... y se ha iniciado otra. Las escrituras colindantes de Rivera Garza trazan trayectorias en y a través de otros medios, otros soportes, otros textos. Y aquí, en este punto, nos vienen a la mente aquellos versos de "la gramática del lugar", publicados en Los textos del Yo (2005b) pero cuya versión digital anterior databa del 2003, cuando No hay tal lugar empezaba uno de sus muchos recorridos: "Aquí, arsénicamente, en la coyuntura adverbial / de los venenos nimios / pronunciaba la palabra utopía / no hay tal lugar / y el animal deseoso y cavilante hurgaba la iluminada / orilla de lo real. / Aquí, en el lenguaje, el único lugar" (91). Quizás, después de todo, el lenguaje, la re-escritura, el laboratorio del lenguaje... y la re-escritura nuevamente: todo emerge como un lugar único: un único lugar.

\section{VLM: el Diario de lecturas como bibliomaquia}

Vicente Luis Mora es un autor prolífico. Su figura podría resumirse bajo la advocación del polígrafo, el lector omnímodo, el "críticoescritor". Ha publicado una variada obra móvil, constantemente en fuga y en deslizamientos entre literatura e imagen. Una escritura que atraviesa géneros y entre cuyas estaciones se encuentran $\mathrm{La}$ luz nueva (2007), El lectoespectador (2012), Autobiografía (2003), Construcción (2005), Tiempo (2009), Pasadizos. Espacios simbólicos entre arte y literatura (2008), Pangea: Internet, blogs y comunicación en un mundo nuevo (2006), Singularidades: ética y poética de la li- 
teratura española actual (2006) y un largo etcétera. Todas sus obras cruzan el ensayo, la crítica, la narrativa, la poesía. Su Diario de lecturas -su blog: [http://vicenteluismora.blogspot.com/]- no es ajeno a todos esos cruces y deslizamientos. Bajo el usuario "VLM", entre 2006 y 2020 publicó 475 posts. En todos esos años no ha habido ninguna interrupción significativa. Apenas sí, una variación de la intensidad. El pico de la actividad se centra entre 2008 y 2009. En términos de su “evolución”, de la cartografía del blog -Mora insiste que la vieja idea de "mapa" resulta obsoleta cuando nuestro objeto pasa a ser digital-, podríamos decir que las características que seńalábamos a propósito de Cristina Rivera Garza, su carácter de "laboratorio" y de constante work in progress, también se comprueban en el Diario de Mora. ${ }^{10}$

\section{Una bibliomaquia heterodoxa}

El género que prima en sus posteos es heterogéneo, tomado por los deslizamientos entre literatura e imagen que él mismo señala en la bajada de El Lectoespectador. Sus intervenciones van desde el artículo académico a la elegía literaria, pasando por las encuestas: a escritores, a lectores de su propio sitio. También aparecen intervenciones sobre arquitectura, sobre series, sobre discursos de, por ejemplo, el ex-presidente de los EE.UU.: Barack Obama. También

${ }^{10}$ Este carácter procesual del blog sirvió, en la lectura de Alex Saum-Pascual (2019), como prisma para analizar la obra literaria de Mora, en particular su novela Circular 07. Las afueras (2007). Se trata de un punto en el que la investigadora insiste: en otro trabajo, para analizar, en otra novela de Mora, Alba Cromm (2010), las tensiones entre el proceso creativo digital y el producto impreso, acuña el término de "escritura \#postweb" para referirse a una literatura que "se ha generado por y para los medios digitales y que ha asumido plenamente la web como algo que ha dejado de ser novedad y futuro para ser presente" (Saum-Pascual, 2018: 10). 
hay "cut \& ups" con noticias y fragmentos literarios. Promociones de sus obras o flyers de sus presentaciones aparecen en cruce con la crónica de viajes, la recomendación literaria y un largo etcétera. Pero, desde el título, Mora nos indica que su blog trata sobre un diario y no cualquier diario sino uno de lecturas. De allí que el género que dominará será el de la reseña. En Cómo se escribe el diario intimo (1997), Alan Pauls seńalaba que el diario nunca aparece sino que se encuentra. En el centro del género hay un cadáver y es el del propio autor. Así es como también debe leerse esa fatalidad sensacionalista del género, que se constituye como un documento póstumo, imaginado, para una posteridad hipotética, eventual, también imaginada. Posteridad imaginada de por medio, el Diario de lecturas puesto en línea aparece en contacto con un puro-presente. Y a diferencia de aquella definición del diario íntimo pergeñada por Pauls en la edad de los impresos, el diario de Mora -entre el blog y también sus eventuales transformaciones en libro impreso- se constituye en un tiempo presente radical, sincrónico y no diacrónico, en una virtual simultaneidad entre escritura y distribución, tal como el mismo crítico-escritor, desde una autoconciencia y autorreflexividad extremas, señala en varias ocasiones. Así como Pauls señalaba que todo diario incluye su declaración de principios, a lo largo de la lectura el blog de Mora también alcanza su justificación. Una de las mutaciones que vale la pena comentar, como modo de apreciar la evolución propia del "diario", es la incorporación el 10 de abril de 2009 de las "videoreseñas". Las videoreseñas aparecerán esporádicamente en el blog y, aunque algunas de ellas devienen luego en "fósiles web" para un museo de restos, muchas otras sin embargo perviven todavía a modo de "entradas activas". Preocupado por el uso productivo pero también desviado de las tecnologías, las videoreseñas imponen, en un escenario marcado por la ilusión de una "inmaterialidad digital", el valor y el espesor del cuerpo. Al mismo tiempo las videorese- 
ñas, presentadas por el propio Mora, escenifican una gestualidad: las expresiones en el rostro de quien habla, el movimiento de sus manos, el tono de la voz de quien lee un poema con una montańa o un lago de fondo. Las videoreseñas llevan literatura a lugares ya cargados de una poeticidad natural preexistente. Y ponen el foco en la "locación": como por ejemplo en Madrid, un pequeño pueblo de 149 habitantes ubicado en Nuevo México, EE. UU. ("Videoreseña en Madrid, New Mexico”, del 21 de marzo de 2010); o en la Laguna del Apoyo en Nicaragua (en la "Video-reseña (con caballos) de la última novela de Germán Sierra”, entrada del 30 de junio del 2009); o en El Malecón de la Habana, por ejemplo (en la video-reseña "Comentario sobre la poesía de Eduardo Moga", del 27 de enero de 2015). ${ }^{11}$ En las "videoreseñas", todo comunica. En este sentido, nos encontramos en las postrimerías de la propia concepción de Mora, para quien, si bien la pantalla a la que nos enfrentamos es material, lo que se proyecta en ella no lo es y la imagen es "intangible, compuesta por bytes de información" (Mora, 2007a), marcada por una concepción un tanto heterodoxa del simulacro baudrillardiano y una reactivación de la filosofía escéptica. Esa "inmaterialidad”, como se sabe desde la filosofía de la técnica, es simplemente otro tipo especial, singular, de materialidad.

${ }^{11}$ Así como en El Lectoespectador (2012) y en Pangea (2006c) Mora plantea un frisamiento de la geografía global, un retorno a la edad pangeica por interpósito de la era digital, algo de esto también alimenta la elección de las locaciones para las videoreseńas. El crítico va a un Madrid de Nuevo México, en EE. UU.; y del mismo modo va hasta la ciudad de Granada, no la de Andalucía sino a la de la costa oeste de Nicaragua. Las videoreseńas y los viajes, modos de un estrechamiento crítico de la geografía. 


\section{Ocultar la Teoría / Mostrar la Lectura}

Los textos de Mora están marcados por la avidez, la bibliomanía, la grafomanía. En paralelo a su trabajo como escritor, crítico, profesor, Mora sostiene un blog que se extiende durante catorce años, ininterrumpidamente activo, incluso cuando lo que podríamos llamar "la era de los blogs" ya ha entrado, al parecer, en una etapa de franco declive. Mora es un "lector omnívoro". No es sencillo reponer una lista exhaustiva de todos sus objetos. Conforme con su postulación de una Edad Pangeica - una nueva era de literatura global, internacionalista, no-nacional-sus lecturas se extiende por diversas latitudes: Argentina, el Caribe, Alemania. Su lectura Pangeica apunta no solo al carácter transnacional e interconectado de la literatura y la cultura contemporánea, sino que también frisa a la geografía y al tiempo. Góngora es un objeto de su pensamiento. Los estudios sociológicos también son otros de sus objetos. La filosofía, la crítica. Pero su objeto fundamental, indudablemente, es la literatura espańola contemporánea. Sus ejercicios de "distant reading" están cruzados con un gran archivo teórico, un gran fondo literario, una desprejuiciada acumulación de citas proliferantes. Esta obsesión intertextual puesta en blog, visibiliza un archivo de las potencias de lo literario y del pensamiento sobre el arte, al tiempo que pone en escena un imperativo personal de la teoría: el de "estar uno a la altura de lo leído" (Mora, 2006a). Mora hace un uso estratégico de la teoría, marcada por una "iluminación circunstancial o contingente". Este hecho también explica el carácter ecléctico de sus lecturas. Aunque en una entrada señala que "cada vez me interesa más ir uniendo aspectos sociológicos con los literarios" (Mora, 2006b), con su respectiva argumentación, el análisis puntual de sus entradas muestra que en Mora la lectura es una relación dinámica marcada por la tensión y la resistencia. Así, pasa del formalismo inmanente al uso de temas; o de la sociología de la 
literatura a las literaturas comparadas. Caracterizado todo con mucho diálogo interdiscursivo: entre literatura y filosofía, literatura, ciencia. El blog asume así un tono específico. El de una grafomanía, tomada por un "enjambre conceptual" sinuoso y huidizo. Si sus libros están marcados por hipótesis amplias y la lectura sistemática, y sus artículos se caracterizan por la exhaustividad respecto de los problemas que abordan, las entradas de su blog en cambio son libres y lúdicas. Como propias de una "crítica al uso". Como si todo el trabajo teórico de Mora quisiera disimularse, ocultarse, perderse en el discurrir de voces proliferantes de la web. Pero por sobre esa distinción se impone una distinción todavía más honda. Aunque Mora a veces anota lo que podría llamarse una "reseña periodística", meramente estructurada alrededor de una crítica del gusto o la sinopsis; el tono de las entradas de su blog es sin embargo el de una "voz media": entre la academia y el periodismo, entre el ensayo y la reseńa. Casi siempre trata de establecer series literarias, yuxtaposiciones inéditas o montajes teórico-literarios de interés, marcados formalmente por un aparato crítico con su unidad mínima: la nota al pie. Esos recursos expresan el volumen del trabajo que Mora imprime en sus entradas. Cuando se presenta una excepción, el autor español lo anota: "Este extraño ensayo, escrito -insisto- sin los medios bibliográficos suficientes para hacerlo" (Mora, 2011a). Esta "voz media" abre las posibilidades para experimentar libremente con los modos críticos de leer. Y en ello se concentra el carácter lúdico, laxo, de su tono crítico. La "lectura riechmanniana de Chejfec o lectura chejfequiana de Riechmann" escribe a las 4:19 p. m. en una entrada del sábado 5 de diciembre del 2015. Del mismo modo, las extensas y omnipresentes notas al pie -donde elabora sus verdaderos argumentos- contrastan con la mera sinopsis conceptual que expone en la entrada del 2 de marzo del 2015, a propósito de la trilogía novelística Las huellas de Jorge Carrión. Como si, en ese singular post, toda la potencia crítica del 
Diario de Lecturas estuviera puesta más en el aparato de las citas que en el cuerpo del texto, en la entrada propiamente. "Dignidad de movimiento", diría Ernest Hemingway. "Narrar [hacer crítica] es saber elidir", diría Ricardo Piglia. El crítico, no puede decir todo lo que sabe, diría Mora. Este contraste entre la sinopsis general y la crítica concentrada de las notas también aparece como uno de sus modos lúdicos de hacer crítica. En un summum de estos ejercicios lúdicos de la crítica aparece la entrada del 16 de diciembre del 2018: un "collage de citas" para que la obra de César Aira "se explique por sí misma”. Una mínima intervención crítica, la diferencia operativa del recorte -los títulos de los apartados- y la yuxtaposición de citas que se iluminan unas a otras, en un encadenamiento cuya potencia es la de suponer un "hilo rojo" autoexplicativo en la obra del escritor argentino. Cómo último ejemplo de heterodoxia crítica en el blog, también se pueden mencionar la serie de entradas que comienzan con "Extractos de un diario inexistente", del 2 de octubre de 2016, donde la lectura se transforma en una mezcla de "andanzas" autobiográficas con comentarios de textos.

\section{Una Autoconciencia Radical}

La escritura de Mora muestra permanentemente las marcas de su hiperconciencia lectora. Mora -lo sabe, lo dice, lo subraya- parte de una gran hipótesis general: la cibercultura afecta las maneras de leer. Su blog, a su modo, es uno de esos lugares donde esa transformación se documenta. Diario de lecturas es el diario, la crónica, el itinerario de un crítico atravesado por los avatares de la era digital: con sus contradicciones, sus tensiones, los diálogos entre la cultura libresca y las pantallas. El blog se presenta como una forma por antonomasia de la democracia del pensamiento sobre el arte, donde se expresa que el patrimonio cultural se defiende mejor desde un "nosotros" que partiendo de un "yo". El blog es 
"necesariamente superficial", breve e inmediato, presionado por una fecha de entrega de ese puro presente que brinda el contacto interactivo con los lectores, los seguidores. Aunque Mora es cuidadoso a la hora de valorar el corpus inabarcable de los blogs, considera que son "ricos en posibilidades", en particular, por el intercambio interactivo, el diálogo transversal con los lectores y la "posibilidad de respuesta” que ellos suscitan (Mora, 2009). En los blogs se performa la posibilidad de "opinar en tiempo real sobre él", en donde "se produce una novedad y los blogs pueden hacer opinión o arte sobre él en cuestión de minutos" (Mora, 2009). Las nociones de "valor" o "alta literatura" no aparecen en el Diario de forma excluyente. El Diario es más bien un "espacio generoso, abierto a otros (a otros autores y a otros espacios)” (Mora, 2009), que introduce una mutación en los modos tradicionales de leer: el scroll frente al movimiento lineal. En Mora se evidencia una polaridad dinámica entre la preocupación y la despreocupación por los aspectos más formales y editoriales del blog. Por un lado, en una entrada, el escritor-crítico señala que poco a poco va dotando de contenido la "barra derecha” del sitio, identificándose (pero no comparándose, esta distinción es clave) con la operación derrideana de Glas, donde se introduce una indecibilidad respecto de cuál es la jerarquía entre los diferentes cuerpos de los textos. Por otro lado, como anota un comentarista anónimo del blog -el Diario de lecturas es susceptible de las críticas de sus propios lectores- las entradas presentan variedad de fuentes, tamaños y colores. A veces esa variedad es intencional, porque así se lo señala. Pero otras veces no. Señal de que las tecnologías "estetizan" a los textos. Y cuando no, también editan y moderan la lectura. 


\section{Postear los comentarios a un Post}

La habilitación de comentarios en el blog configura una zona efervescente, un intenso lugar de intercambios productivos con los efectivos lectores del Diario. Algunas de sus entradas llegan a ser incluso meras recopilaciones de los intercambios suscitados con otros lectores virtuales. Entre ellos se destaca, indudablemente, Agustín Fernández Mallo, autor de su propio blog [El hombre que salió de la tarta: http://fernandezmallo.megustaleer.com/] y asimismo asiduo participante en el Diario de lecturas de Mora. El tono que domina en sus comentarios es el de la cortesía crítica, el intercambio libre, la polémica amistosa. El tono de esos intercambios podrían compararse, como ellos mismos lo hacen, con el de los salones literarios del siglo XIx. Aquí se puede introducir una hipótesis fuerte: contra las perspectivas de disolución del campo literario (Ludmer) o de su declinamiento estructural (Maingueneau), más cercano con la propuesta de Diego Vigna (2014), el Diario de lecturas de Mora demuestra una suerte de supervivencia póstuma del campo como juego de lecturas. El intercambio de los comentarios es clave para la discusión colectiva sobre el estatuto y el valor de la literatura en el escenario contemporáneo. En algún momento Mora llega a defender el espacio de los comentarios desde un punto de vista legalista, insertando allí una "advertencia": "De acuerdo con el nuevo Reglamento General de Protección de Datos, la persona que quiera dejar un comentario lo hace con conocimiento de sus derechos [...] Al dejar un comentario, se entiende que da al administrador del blog su consentimiento para publicarlo y que conoce la política de privacidad" (Mora, 2018).

Hay allí toda una política de la amistad, sometida, claro está, antes a toda una política de la lectura. En la entrada del 24 de enero del 2007, sobre el poemario Cortes publicitarios de Javier Moreno, Mora nos ilustra el placer que le produce comentar este texto en Diarios de 
lecturas, no solo por su valorable exploración estética sino también porque, y fundamentalmente, "su autor siempre ha sido, desde los comienzos de este blog, uno de los más interesantes y combativos comentaristas" (Mora, 2007b). Pero en la aclaración de Mora no se señala cuál ha sido el seudónimo utilizado por Javier Moreno para insertar sus comentarios en el Diario de lecturas, lo cual se convierte luego en un conflicto, desatando una nueva secuencia de comentarios. De modo tal que un post al libro de un comentador del blog genera más comentarios: Comments en abyme.

Un caso paradigmático, como ya señalamos, es el de Agustín Fernández Mallo: autor él también de un blog, comentarista del Diario de lecturas, amigo personal de Mora, renovador indudable de la narrativa española contemporánea, punto de partida de lo que se llamó "generación Nocilla", "generación Afterpop" o "escritores mutantes". Al respecto Mora ha sido muy claro en afirmar que para él "ni hay generación, ni hay grupo, ni hay Nocilla: lo que hay es una agrupación, no de almas gemelas, que es un poco cursi, sino de inquietudes intelectuales parecidas, que sin embargo generan obras estéticas distintas e incluso contrapuestas" (Mora, 2007c). Mora entiende que en lo que se ha dado en llamar "Generación Nocilla" no hay una estética sino oportunismo del periodismo cultural y del mercado, y que la tan mentada novedad de sus mayores exponentes (Agustín Fernández Mallo, por caso) está excesivamente forzada. Esa crítica no le impide a Mora tener acceso y publicar, en una entrada del 28 de febrero de 2008, un adelanto "exclusivo" de un fragmento de su Nocilla Experience, lo que desata un conflicto interno. Es la amistad con Fernández Mallo la que permite ese post. Y es la declamación de una "ética" de la lectura en entradas anteriores, la que introduce algunas entradas a su manera "dramáticas" dentro del Diario. En la entrada "Autocrítica", del 14 de abril del 2008, Mora señala que frente a su intención de que el blog se mantuviera como un espacio literario al margen del mer- 
cado, haber incluido en su Diario un adelanto editorial, aunque no se tenga ninguna relación con la editorial específica de la que se trata, lo ha hecho incurrir en una grave contradicción: "aunque mi intención no fuera espuria ni mercantilista, cometí un error al reproducir, siquiera inconscientemente, esquemas del mercado, técnicas ligadas a la mercantilización de los productos literarios" (Mora, 2008a). Este problema del mercado, como veremos, es clave para entender el modo de leer de Mora. La amistad entre ambos se acentúa y radicaliza con el tiempo. Intentando escapar de un "nepotismo literario" que acosa el campo intelectual, Mora decide que, a partir de cierto momento, explicitará tanto la relación personal con el autor del libro, como con la editorial. No se trata, por supuesto, de enarbolar una suerte de imparcialidad imposible, sino más bien de un gesto de transparencia para con sus lectores, de honestidad intelectual para consigo mismo. Louis Althusser diría, parafraseando: "puesto que no hay amistades inocentes, empecemos por confesar de qué amistades somos culpables".

Hay quienes podrían ver una sobreactuación de la distancia crítica en ese gesto. Cuando Mora comenta Postpoesía de Fernández Mallo no escatima allí ni sus falencias ni, según sus palabras, sus "modestos aciertos". El cénit de este capítulo dramático llega cuando Mora decide, en un descargo del 1 de Diciembre del 2009, que también puede ser leído como auto-exposición límite, confesión, sobre-actuación en bucle, distanciarse del grupo "anti-grupo" de los Nocilla. Las razones son varias, incluso llega a señalar algunas actitudes interpersonales que le molestaron de algunos de sus integrantes y un "encorsetamiento" de las prácticas y la presentación social. La más significativa es que él mismo se considera como un individuo "no agrupable". El argumento expresado parece ser más psicologista que de otro tipo. No podemos dejar de ver sin embargo allí cierta resistencia a la voluntad colectiva de las vanguardias históricas con las que los Nocillas, con muchas y explicitadas reser- 
vas, a su modo se emparentan, renovación de la literatura mediante. Todos los avatares de la lectura en el Diario, con su declarada "ética de la crítica" y con sus protocolos de Protección de Datos para los Comentaristas - protección de Datos y declaración de derechos que los expone abiertamente a las consecuencias de que se publiquen sus comentarios- envuelven todo el gesto del blog dentro del halo Remodernista. El autor del Diario -su figura, su tono de la enunciación- emerge allí efectivamente tomado por el aura romántica del autor individual. La argumentación del descargo llega a su punto más autocrítico cuando señala que quizá su error fue haber sido parte del grupo como escritor y, al mismo tiempo, pretender ser uno de los teóricos del movimiento. A partir de este razonamiento, en un momento dado Mora decide abstenerse de publicar comentarios y reseñas sobre los “mutantes”.

\section{+/-: Arte Más Menos Mercado}

Mora se muestra insistentemente preocupado por la cuestión del canon, relacionándolo con otros dos focos de interrogación. En primer lugar, la cuestión del mercado, una obsesión de los Nocilla. En la entrada "Paseo por ARCO", del 19 de febrero del 2007, Mora anota: "A mi juicio, hay arte y mercado, dividido el espacio de esta forma: 1) Arte sin mercado; 2) Arte más mercado; 3) Arte menos mercado; 4) Mercado" (Mora, 2007d). Alejado del despreocupado tono de Agustín Fernández Mallo, Mora en una entrada expone su escándalo frente a los autores que se jactan de ideología progresista para luego adoptar en su obra estrategias de mercado, poniendo así en un segundo plano sus preocupaciones estéticas. Se trata, nuevamente, de un problema complejo, cuando no incluso de un dilema. Mora llega incluso a criticarse a sí mismo por, en ciertas ocasiones, haber incurrido él también en ese gesto. En la entrada "Inmaterialidad y mercado", del 3 de septiembre de 
2007, señala que el valor del mercado en el capitalismo informático es la reciclabilidad inmediata, no dejando de indicar el placer que siente cuando "sus productos se destruyen apretando el botón de suprimir” (Mora, 2007a). Pero el principio ético que domina en Mora es una suerte de suspicacia sutil, que seńala la indeseabilidad absoluta de que los dilemas estéticos sean sustituidos por la lista de los libros más vendidos.

Respecto de la relación Canon/Mercado, siguiendo postulaciones como las del "fin de los metarrelatos" (Lyotard) y el "sublime capitalista" (Jameson), se vuelve complejo el restablecimiento de un canon. Éste requiere precisamente de un relato maestro para su organización y selección de las obras, así como de una percepción no-sublime del campo literario - es decir, una no pérdida en la incapacidad de aprehender la extrema proliferación del mercado literario contemporáneo-. Respecto de esta relación, e incurriendo en el debate en torno a la posmodernidad, Mora explícitamente asegura que él no se considera un escritor precisamente posmoderno, pero, aún así, reconoce su capacidad para apreciar poéticas posmodernas: "metaliteratura, autorreferencialidad, intertexto, ironía, pastiche, parodia, post-genericidad, ideología débil, híbridez, cuestionamiento del poder y de los grandes relatos" (Mora, 2011a). Esta adscripción no es acrítica. En varias ocasiones, respecto a algún libro en particular, señala los excesos artificiosos de estos recursos y características. Aunque no lo problematiza explícitamente, podríamos hipotetizar que él estaría de acuerdo en señalar que ya no hay un Canon, sino múltiples cánones alternativos, organizados según criterios y éticas diferentes: un canon feminista, un canon poscolonial y así sucesivamente. No parece difícil relacionar la correlatividad entre el carácter "alternativo" de los cánones y la dinámica de superespecialización de la mercancía en el capitalismo tardío, por lo que el problema del canon vuelve a anudarse con el problema 
del mercado. Posts en abyme. Efectos ("colaterales") del mercado en el campo cultural.

\section{Crítica en red: Poner Orden en el Caos / Subvertir el Orden del Mercado}

El concepto de canon se anuda con la cuestión -actual, inactual, anacrónica- del valor literario y, por ende, de la crítica literaria. ${ }^{12}$ En una entrevista también publicada en su blog, donde le preguntan sobre la función de los estudios literarios en la actualidad, Mora responde: "Hace diez años le hubiera dicho que su función era poner orden en el caos, pero ahora, ante la funesta normalización cultural, creo que su función debe ser la contraria: subvertir los procedimientos de canonización mercantil establecidos" (Mora, 2008b): desorganizar el campo industrial, subvertir el orden del mercado. Aunque la defensa de una "escritura alternativa" que no se deje llevar por el mero valor del entretenimiento es una constante en Mora, la pregunta sobre la función de la crítica despierta respuestas contradictorias. No mucho después de señalar la necesidad de "subvertir la canonización mercantil", anota que una de las tareas de la crítica literaria en nuestros días consistiría en "fijar poco a poco el corpus de obras de finales del [siglo] xx" (Mora, 2016). Algo similar parece desprenderse de todo el trabajo de Rivera Garza, para quien el canon posee todavía un vitalismo del presente, algo todavía activo a partir de los apropiacionismos de la lectura. Es precisamente ese vitalismo del canon el que le permite tomar la tradición y hacerla propia: "Habrá que recordar

${ }^{12}$ A propósito del peso de la tradición: en su entrada del 11 de enero del 2008 se ocupa del nuevo himno nacional español: un claro ejemplo, para él, del escaso valor estético del canon cultural oficial en España. 
de vez en cuando que la 'tradición' solo se puede escribir en plural y con minúsculas" (Rivera Garza, 2004g).

No se trata, nuevamente, de la inexistencia del canon, sino de no someterse a una forma específica de canonización, la que introduce la sobrevaloración, por ejemplo, de "los más vendidos". El filo que separa esta resistente unidad es la apelación al valor literario. Y eso encarna una lucha. Mora señala que el campo intelectual español "ha optado secularmente por eliminar el criterio de calidad como modo de referirse a las obras poéticas" (Mora, 2019), una cordialidad complaciente contra la que Mora mismo se siente no solo exterior sino, como vimos, interiormente interpelado. Para él, la crítica es "una auténtica evaluación estética de los textos leídos" (Mora, 2019), hecho en el que el despliegue textual del Diario de lecturas se impone como un paradigma evidentemente consistente.

En su centenar de reseñas, Mora no escatima juicios estéticos. Si bien en su mayoría sus críticas son benevolentes, en otros casos, asumen la forma de una diplomacia elegante para poner en evidencia faltas y desaciertos: "En efecto, hay que decirlo, tanto lo bueno como lo malo, porque de otro modo no se hace crítica literaria, sino pura palabrería gastada y gestualidad ampulosa de cara a la galería” (Mora, 2019). Entre tanto, Rivera Garza hace de su propia obra un lugar de representación del pasado [a la pregunta de si-hay-tal-lugar: SÍ-hay-tal-lugar es la respuesta], el modo en que la reedición de la modernidad de la literatura todavía se realiza. La literatura misma aparece entonces como ese relato matriz que organiza la tradición literaria.

Así, el valor literario y el canon emergen como un problema capital de los modos de leer en la era digital, en cristina, en crg, en Cristina Rivera Garza, en Mora, en VLM, en Vicente Luis Mora, en ellxs, en nosotrxs, en aquel tiempo y en el nuestro: el siglo xx, el siglo Xxi. La literatura aparece como el lugar mismo de reescrituras de la historia. Y el Remodernisno -las maneras de leer en la mo- 
dernidad- todavía en los umbrales del posthumanismo. Aunque la ausencia de un relato maestro del presente parece debilitar nuestras maneras de leer, la de los otros, la de todos, transformándolas en contingentes, provisorias, quizá no se trate tanto de constituir un nuevo relato maestro, sino de advertir la permanencia, la vigencia, la potencia, el vigor, de un relato maestro pergeñado en la Modernidad y todavía sumamente activo en aquellas reescrituras que, como la mirada del Angelus Novus de Paul Klee evocado en las Tesis de Filosofía de la Historia de Walter Benjamin, todavía es capaz de hacer una pausa aun estando en medio de los torbellinos del presente: hacer una pausa, mirar por un momento a los costados, hacia atrás, y ver el modo en que allí se apila ruina sobre ruina, lectura sobre lectura, futuro sobre futuro.

La literatura, la (re)escritura, es quizá ese relato maestro que, aunque parezca debilitado y movido por la inercia, todavía resplandece bajo la apariencia de unos restos. A la espera de un tono, un nuevo relato maestro - una nueva literatura- que le restituya su exacto valor histórico. Dada la estructura del juicio estético, se parte de una subjetividad, pero, como bien lo señala Vicente Luis Mora para la forma-blog, tal como lo evidencia Cristina Rivera Garza en sus reversiones de la modernidad latinoamericana: una subjetividad que es más un "nosotros" que un "yo". El llamado final es el de reestablecer la necesidad de una misión colectiva, una auténtica bibliomaquia heteronormativa para la lectura.

\section{Bibliografía}

Barthes, Roland, 1986, "Deliberación", en Lo obvio y lo obtuso. Imágenes, gestos, voces, C. Fernández Medrano (trad.), Paidós, Barcelona, pp. 365-380. 
Bourriaud, Nicolas, 2014, Postproducción. La cultura como escenario: modos en que el arte reprograma el mundo contemporáneo, Silvio Mattoni (trad.), Adriana Hidalgo (ed.), Buenos Aires.

,2018, Radicante, Michèle Guillemont (trad.), Adriana Hidalgo (ed.), Buenos Aires.

Choi, You-Jeong, 2006, "La literatura en el mundo virtual: Los escritores y el 'blog' en América Latina”, Espéculo: Revista de Estudios Literarios, año XI, núm. 33, julio-octubre. Disponible en: https://webs.ucm.es/info/especulo/numero36/cibliter.html

,2007, "No hay tal lugar: la ciberliteratura de Cristina Rivera Garza”, Espéculo: Revista de Estudios Literarios, año XII, núm. 36, julio-octubre. Disponible en: https://webs.ucm.es/info/especulo/numero36/cibliter.html

, 2010, "No hay tal lugar: la blogsívela de Cristina Rivera Garza”, en Cristina Rivera Garza, Ningún critico cuenta esto..., Oswaldo Estrada (ed.), Ediciones Eón, México, pp. 282-231,

Cruz Arzabal, Roberto, 2014, "Dispositivos artísticos post-digitales: escrituras de ida y vuelta”, en Red de Humanidades Digitales, 18 de abril. Disponible en: http://humanidadesdigitales.net/ blog/2014/04/18/dispositivos-artisticos-post-digitales-escrituras-de-ida-y-vuelta/

,2016, "Archivos potenciales: domiciliación y colindancias en Viriditas de Cristina Rivera Garza”, Letras femeninas, vol. 2, núm. 42, pp. 35-43.

Griboul, Françoise, 2006, "Ecriture errante. Navigation dans les blogs d'une écrivaine mexicaine: Cristina Rivera Garza”, en Les Textes et ses liens I, Milagros Ezquerro (dir.), Indigo \& Coté Femmes Editions, París, pp. 143-56.

Keizman, Betina, 2013, "El blog de Cristina Rivera Garza: experiencia literaria y terreno de contienda”, Chasqui, vol. 1, núm. 42, pp. 3-15. 
Kozak, Claudia, 2015, "Introducción”, en Tecnopoéticas argentinas. Archivo blando de arte y tecnología, Claudia Kozak (ed.), Caja Negra Editora, Buenos Aires, pp. 9-12.

Laddaga, Reinaldo, 2010, Estética de laboratorio. Estrategias de las artes del presente, Adriana Hidalgo Editora, Buenos Aires.

Mendoza, Juan José, 2011a, "El imperio textuario", en El canon digital, La Crujía, Buenos Aires, pp. 99-113.

,2011b, Escrituras past_tradiciones y futurismos del siglo 21, 17 grises, Buenos Aires.

, 2014, "Teoría y Crítica de la literatura española contemporánea en el contexto internacional de la literatura", Olivar, vol. 15, núm. 21, pp. 23-32. Disponible en: http://www.memoria.fahce.unlp.edu.ar/art_revistas/pr.6624/pr.6624.pdf

, 2016, "El Remodernismo. Literatura Argentina y después [un ensayo]", El Matadero, núm. 10, Buenos Aires, pp. 69-82. Disponible en: http://revistascientificas.filo.uba.ar/index.php/ matadero/article/view/4972.

Mora, Vicente Luis, 2006a, "Ashbery y su Autorretrato: retrato de un libro en dos tiempos" [Entrada en blog], Diario de lecturas, 31 de octubre. Disponible en: http://vicenteluismora.blogspot. com/2006/10/ashbery-y-su-autorretrato-retrato-de.html

2006b, "Hamburguesas y poesía" [Entrada en blog], en Diario de lecturas, 11 de noviembre. Disponible en: http://vicenteluismora.blogspot.com/2006/11/hamburguesas-y-poesacada-vez-me.html

, 2006c, Pangea: Internet, blogs y comunicación en un nuevo mundo, Fundación José Manuel Lara, Sevilla.

, 2007a, "Inmaterialidad y mercado" [Entrada en blog], Diario de lecturas, 3 de septiembre. Disponible ne: http://vicenteluismora.blogspot.com/2007/09/inmaterialidad-y-mercadola-gestin.html 
, 2007b, "La Palmera - virtual - del fondo de la mente" [Entrada en blog], Diario de lecturas, 24 de enero. Disponible en: http://vicenteluismora.blogspot.com/2007/01/la-palmeravirtual-del-fondo-de-la.html

, 2007c, "Materiales (diversos) para entender la nueva narrativa" [Entrada en blog], Diario de lecturas, 24 de octubre. Disponible en: http://vicenteluismora.blogspot.com/2007/10/ materiales-diversos-para-entender-la.html

, 2007d, "Paseo por ARCO" [Entrada en blog], Diario de lecturas, 19 de febrero. Disponible en: http://vicenteluismora. blogspot.com/2007/02/paseo-por-arco-slo-escombros-gracias. html

,2008a, "Autocrítica" [Entrada en blog], Diario de lecturas, 14 de abril. Disponible en: http://vicenteluismora.blogspot. com/2008/04/autocrtica.html

, 2008b, "Cuestionario de Fruela Fernández" [Entrada en blog], Diario de lecturas, 12 de junio. Disponible en: http://vicenteluismora.blogspot.com/2008/06/cuestionario-de-fruelafernndez.html

2009, "Conferencia sobre blogs y literatura" [Entrada en blog], Diario de lecturas, 12 de junio. Disponible en: http:// vicenteluismora.blogspot.com/2009/06/conferenencia-sobreblogs-y-literatura.html

, 2011a, "Gongora: del zapping al overlapping" [Entrada en blog], Diario de lecturas, 26 de abril. Disponible en: http:// vicenteluismora.blogspot.com/2011/04/gongora-del-zappingal-overlapping_26.html

, 2011b, "Prospecciones sobre Posmodernidad y poesía espańola" [Entrada en blog], Diario de lecturas, 30 de enero. Disponible en: http://vicenteluismora.blogspot.com/2011/01/ prospecciones-sobre-posmodernidad-y.html 
, 2012, El Lectoespectador. Deslizamientos entre literatura e imagen, Seix Barral, Barcelona.

, 2016, "Trece años de Fabulosas narraciones por historias" [Entrada en blog], Diario de lecturas, 13 de noviembre. Disponible en: http://vicenteluismora.blogspot.com/2016/11/ veinte-anos-de-fabulosas-narraciones.html

, 2018, "Nunca hay demasiado Milán" [Entrada en blog], Diario de lecturas, 11 de junio. Disponible en: http://vicenteluismora.blogspot.com/2018/06/nunca-hay-demasiado-milan. html

, 2019, "El conflicto producido por la llegada de la poesía pop tardoadolescente" [Entrada en blog], Diario de lecturas, 15 de septiembre. Disponible en: http://vicenteluismora.blogspot. com/2019/09/el-conflicto-producido-por-la-llegada.html

Pantel, Alice, 2018, "Blog y legitimación cultural en la narrativa española”, Revista Letral, núm. 20, julio, pp. 24-38.

Pauls, Alan, 1997, Cómo se escribe un diario intimo, El Ateneo, Buenos Aires.

Rivera Garza, Cristina, 2003a, "Blogsívela 2003. LXXXXIII. Estertor" [Entrada en blog], Words are the very eyes of secrecy, 29 de diciembre. Disponible en: https://web.archive.org/ web/20040107152315/http://cristinariveragarza.blogspot. com/2003_12_01_cristinariveragarza_archive.html

, 2003b, "Blognovela 2003. XXV. La Autora y la Sívela" [Entrada en blog], Words are the very eyes of secrecy, 26 de febrero. Disponible en: https://web.archive.org/web/20030719050350/ http://cristinariveragarza.blogspot.com/

,2003c, "La blognovela del 2003" [Entrada en blog], Words are the very eyes of secrecy, 1 de enero. Disponible en: https:// web.archive.org/web/20030719050350/http://cristinariveragarza.blogspot.com/ 
, 2004a, "Año bisiesto" [Entrada en blog], No hay tal lugar. U-tópicos contemporáneos, 8 de enero. Disponible en: http:// cristinariveragarza.blogspot.com/2004/01/

, 2004b, "Blogsívela. Escribir a inicios del siglo XXI desde la blogósfera”, en Palabra de América, Seix Barral, Barcelona, pp.167-179.

,2004c, "Definiciones mínimas" [Entrada en blog], No hay tal lugar. U-tópicos contemporáneos, 13 de abril. Disponible en: http://cristinariveragarza.blogspot.com/2004/04/

, 2004d, "Escribir y olvidar" [Entrada en blog], No hay tal lugar. U-tópicos contemporáneos, 6 de febrero. Disponible en: http://cristinariveragarza.blogspot.com/2004/02/

, 2004e, "Escrituras colindantes" [Entrada en blog], No hay tal lugar. U-tópicos contemporáneos, 10 de julio. Disponible en: http://cristinariveragarza.blogspot.com/2004/07/

, 2004f, "Las lenguas pos-maternas" [Entrada en blog], No hay tal lugar. U-tópicos contemporáneos, 14 de mayo. Disponible en: http://cristinariveragarza.blogspot.com/2004/05/

, 2004g, "Mínimas mundanas" [Entrada en blog], No hay tal lugar. U-tópicos contemporáneos, 16 de agosto. Disponible en: http://cristinariveragarza.blogspot.com/2004/08/

,2005a, "Esto no es un ataque personal en contra del final" [Entrada en blog], No hay tal lugar. U-tópicos contemporáneos, 24 de mayo. Disponible en: http://cristinariveragarza.blogspot. com/2005/05/ México.

, 2005b, Los textos del Yo, Fondo de Cultura Económica, , 2005c, "Pedro Páramo en siete minutos" [Entrada en blog], No hay tal lugar. U-tópicos contemporáneos, 28 de marzo. Disponible en: http://cristinariveragarza.blogspot.com/2005/03/ 
, 2007a, "Duras, la ur-blogger" [Entrada en blog], No hay tal lugar. U-tópicos contemporáneos, 11 de diciembre. Disponible en: http://cristinariveragarza.blogspot.com/2007/12/

, 2007b, "Introducción. Escribir un libro que no es mío", en La novela según los novelistas, Cristina Rivera Garza (coord.), Fondo de Cultura Económica/Consejo Nacional para la Cultura y las Artes, México, pp. 9-16.

, 2010a, "La página cruda", en Cristina Rivera Garza, Ningún crítico cuenta esto..., Oswaldo Estrada (ed.), Ediciones Eón, México, pp. 15-17.

, 2010b, "La tercera vía" [Entrada en blog], No hay tal lugar. U-tópicos contemporáneos, 31 de enero. Disponible en: http:// cristinariveragarza.blogspot.com/2010/01/

, 2010c, "Saber demasiado", en Cristina Rivera Garza, Ningún crítico cuenta esto..., Oswaldo Estrada (ed.), Ediciones Eón, México, pp. 13-14.

, 2010d, "Telegrama 1.0 para dos Increíblemente Pequeñas forajidas" [Entrada en blog], No hay tal lugar. U-tópicos contemporáneos, 27 de octubre. Disponible en: http://cristinariveragarza.blogspot.com/2010/10/

, 2011, El disco de Newton. Diez ensayos sobre el color, Bonobos/Universidad Nacional Autónoma de México, México.

, 2013, Los muertos indóciles. Necroescrituras y desapropiación, Tusquets, México.

, 2017, Habia mucha neblina o humo o no sé qué, Literatura Random House, Buenos Aires.

Ryan, Marie-Laure, 2013, "Transmedial Storytelling and Transfictionality”, Poetics Today, vol. 3, núm. 34, otoño, pp. 362-388.

Sánchez-Aparicio, Vega, 2016, "Las escrituras alegóricas del software: colapso estético, articulación ética, desde el espacio mexi- 
cano", Caracteres: estudios culturales y criticos de la esfera digital, vol. 2, núm. 5, pp. 80-113.

, 2018, "Respirar en el paisaje de los medios: las poéticas disruptivas de Cristina Rivera Garza”, Revista Landa, vol. 1, núm. 7, pp. 212-231.

, 2019, "Grietas textuales y discursos interrumpidos: el recurso del glitch en las 'escrituras del software”, Digithum, núm. 23, pp. 1-10.

Saum-Pascual, Alex, 2018, \#Postweb! Crear con la máquina y en la red, Iberoamericana/Vervuert, Madrid/Frankfurt.

,2019, "Fragmentation and the Digital City: An Analysis of Vicente Luis Moras's Circular 07. Las afueras", Revista de Estudios Hispánicos, vol. 2, núm. 53, pp. 605-632.

Vigna, Diego, 2014, La década posteada. Blogs de escritores argentinos (2002-2012), Alción Editora, Córdoba. 